\title{
FFE, DFE and MLSE equalizers in phase modulated transmission systems
}

\section{Citation for published version (APA):}

Al Fiad, M. S. A. S., Borne, van den, D., Kuschnerov, M., Spinnler, B., Wuth, T., Napoli, A., Jansen, S. L., \& Waardt, de, H. (2009). FFE, DFE and MLSE equalizers in phase modulated transmission systems. In Proceedings of the 2009 IEEE LEOS Annual Meeting Conference, (LEOS '09) 4 - 8 October 2009, Belek-Antalya (pp. Tul1-193/194). Institute of Electrical and Electronics Engineers. https://doi.org/10.1109/LEOS.2009.5343310

DOI:

10.1109/LEOS.2009.5343310

Document status and date:

Published: 01/01/2009

\section{Document Version:}

Publisher's PDF, also known as Version of Record (includes final page, issue and volume numbers)

\section{Please check the document version of this publication:}

- A submitted manuscript is the version of the article upon submission and before peer-review. There can be important differences between the submitted version and the official published version of record. People interested in the research are advised to contact the author for the final version of the publication, or visit the $\mathrm{DOI}$ to the publisher's website.

- The final author version and the galley proof are versions of the publication after peer review.

- The final published version features the final layout of the paper including the volume, issue and page numbers.

Link to publication

\section{General rights}

Copyright and moral rights for the publications made accessible in the public portal are retained by the authors and/or other copyright owners and it is a condition of accessing publications that users recognise and abide by the legal requirements associated with these rights.

- Users may download and print one copy of any publication from the public portal for the purpose of private study or research.

- You may not further distribute the material or use it for any profit-making activity or commercial gain

- You may freely distribute the URL identifying the publication in the public portal.

If the publication is distributed under the terms of Article 25fa of the Dutch Copyright Act, indicated by the "Taverne" license above, please follow below link for the End User Agreement:

www.tue.nl/taverne

Take down policy

If you believe that this document breaches copyright please contact us at:

openaccess@tue.nl

providing details and we will investigate your claim. 


\title{
FFE, DFE and MLSE Equalizers in Phase Modulated Transmission Systems
}

\author{
M. S. Alfiad ${ }^{1}$, D. van den Borne ${ }^{2}$, M. Kuschnerov ${ }^{3}$, B. Spinnler ${ }^{2}$, T. Wuth ${ }^{2}$, A. Napoli ${ }^{2}$, S. L. Jansen ${ }^{2}$, H. de Waardt ${ }^{1}$ \\ 1: COBRA institute, Eindhoven University of Technology, The Netherlands (m.s.alfiad@ tue.nl) \\ 2: Nokia Siemens Networks, Hofmannstr. 51, Munich, Germany (d.v.d.borne@ieee.org) \\ 3: Federal Armed Forces University, EIT-3, D-85577 Neubiberg Germany (maxim.kuschnerov@unibw.de)
}

\begin{abstract}
We investigate the performance and implementation complexity of different equalization techniques combined with phase modulation. We demonstrate that for data rates $\geq 40-G b / s$, FFE allows for the most efficient equalization of linear transmission impairments.
\end{abstract}

\section{Introduction}

The rapid increase of traffic in backbone networks over the past couple of years has created the necessity for data rate of $40-\mathrm{Gb} / \mathrm{s}$ and, more recently, $100-\mathrm{Gb} / \mathrm{s}$ per wavelength channel. However, at data rates of $\geq 10 \mathrm{~Gb} / \mathrm{s}$, the feasible transmission distance is limited by the residual chromatic dispersion (CD) and polarization-mode dispersion (PMD). Traditionally, these linear impairments are compensated for in the optical domain: $C D$ is compensated for by using dispersion compensating fiber or fiber Bragg gratings and PMD is avoided through fiber selection or compensated with an optical PMD compensator. Equalization of transmission impairments in the electrical domain is a potential alternative to such techniques. It is a mature field in radio telecommunications, where various techniques have been thoroughly studied and can be applied to optical transmission systems, such as maximum likelihood sequence estimation (MLSE), feed forward equalization (FFE) and decision feedback equalization (DFE) [1-4].

In this paper, we will discuss the performance and implementation complexity of MLSE, FFE and DFE when combined with phase modulated transmission formats. Both direct- and coherent-detection receivers in presence of linear transmission impairments are discussed.

\section{Equalization for direct-detection receivers}

In direct-detection receivers, the phase of optical signal is lost through the square law detection in photodiodes. FFE, as a linear equalizer, depends on finding the inverse of the channel's transfer function to effectively equalize the linear transmission impairments. Consequently, it can not be effectively used with direct-detection receivers $[1,2]$. To overcome the limitations of FFE one can consider two solutions: (1) a Volterra equalizer and (2) a MLSE. A Volterra equalizer has a similar structure to FFE with the exception that it takes into account the higher order components in the nonlinear transfer function of channel after direct detection. MLSE, on the other hand, trains the receiver to distinguish the different received sequences in the presence of ISI, instead of compensating for the distortions of the signal. Therefore MLSE does not depend on the linear nature of $C D$ and $P M D$, but rather on the deterministic effect that they introduce on symbols. Both MLSE and Volterra have been shown to be efficient tools for the compensation CD for Duobinary and OOK modulation at data rates of $10.7 \mathrm{~Gb} / \mathrm{s}$ [2-4]. As a result, MLSE has been commercially available for a number of years [3]. However, in [1, 4, 5] it has been demonstrated that neither of the two techniques is capable of compensating the residual CD in $D(Q) P S K$ modulated signals. Hence, in [6] the principle of joint-MLSE was proposed as an alternative structure of conventional MLSE for D(Q)PSK modulated signals. Joint-MLSE is based on having more than one input to the MLSE representing the same signal, and then using a joint probability on the input signals it can provide a better estimation of the received signal. In [5], we experimentally evaluated the performance of the joint-MLSE technique and we proved its potential to significantly enhance the tolerance of the direct-detection receiver against CD. However, a major drawback for joint-MLSE is the need to use double as much ADCs, as well as the extra memory locations for storing the histograms of the extra input signals. In order to overcome the implementation complexity problem of joint-MLSE, we have proposed in [5] the use of a shortened (less than one bit) Mach Zehnder delay interferometer (MZDI) together with a conventional MLSE. Using this approach we showed a CD tolerance of up to $4000 \mathrm{ps} / \mathrm{nm}$ for a $10 \mathrm{~Gb} / \mathrm{s}$ DPSK signal using a 0.5 bit-delay MZDI and MLSE.

\section{Equalization for coherent-detection receivers}

In case of coherent detection, either FFE or MLSE can be used effectively given that coherent detection transfers the amplitude, phase and polarization of optical signal to the electrical domain. In this case, the optimum equalization approach mainly depends on the equalizer complexity. In order to compare MLSE and FFE in terms of complexity, we assume a polarization-diverse coherent receiver. The two outputs of the coherent receiver, representing the two polarizations of the signals, are equalized either through an FFE in a butterfly structure or in a joint- 
MLSE structure. This receiver structure is used to detect a $10.7 \mathrm{~Gb} / \mathrm{s}$ DPSK, $43 \mathrm{~Gb} / \mathrm{s}$ DPSK, $43 \mathrm{~Gb} / \mathrm{s}$ DQPSK or $111 \mathrm{~Gb} / \mathrm{s}$ polarization multiplexed (POLMUX) DQPSK signal. A 2 sample/symbol sampling rate is assumed for the ADCs and the digital signal processing. In table 1 , the number of operations required per symbol is summarized for both FFE and MLSE in presence of CD. Knowing that the signal distribution after coherent detection can be approximated by a Gaussian shape, one can use the parametric MLSE method for this signal. Consequently, in case of MLSE, the computational power requirement is calculated for both the parametric and the histograms methods. The comparison here is only in terms of operations required for equalizing/estimating the signal, while the operations required for training and channel tracking are not included. Note that in case of coherent detection, the total accumulation of CD in the signal can be compensated for using a frequency domain equalizer (FDE) in the electrical domain, however, in this paper we are only referring to the compensation of residual CD in the order of $\sim \pm 1500 \mathrm{ps} / \mathrm{nm}$ after either optical or electrical bulk CD compensation.

\begin{tabular}{|c|c|c|c|c|}
\hline & & \multicolumn{3}{|c|}{$200 \mathrm{ps} / \mathrm{nm}(600 \mathrm{ps} / \mathrm{nm})$} \\
\hline & & $\begin{array}{c}\text { Complex } \\
\text { Summations }\end{array}$ & $\begin{array}{c}\text { Complex } \\
\text { Multiplications }\end{array}$ & $\begin{array}{c}\text { Memory } \\
\text { Locations }\end{array}$ \\
\hline \multirow{3}{*}{$\begin{array}{c}10.7 \mathrm{~Gb} / \mathrm{s} \\
\mathrm{DPSK}\end{array}$} & FFE & $4(12)$ & $4(12)$ & $8(24)$ \\
\hline & MLSE parametric & $21(30)$ & $10(14)$ & $4(11)$ \\
\hline & MLSE Histograms & $21(30)$ & $0(0)$ & $2.5 \times 10^{3}\left(3.5 \times 10^{3}\right)$ \\
\hline \multirow{3}{*}{$\begin{array}{l}43 \mathrm{~Gb} / \mathrm{s} \\
\mathrm{DPSK}\end{array}$} & FFE & $36(100)$ & $36(100)$ & $72(200)$ \\
\hline & MLSE parametric & $306\left(9.8 \times 10^{4}\right)$ & $144\left(4.6 \times 10^{4}\right)$ & $410\left(3.7 \times 10^{5}\right)$ \\
\hline & MLSE Histograms & $306\left(9.8 \times 10^{4}\right)$ & $0(0)$ & $3.7 \times 10^{4}\left(1.2 \times 10^{7}\right)$ \\
\hline \multirow{3}{*}{$\begin{array}{l}43 \mathrm{~Gb} / \mathrm{s} \\
\mathrm{DQSK}\end{array}$} & FFE & $12(28)$ & $12(28)$ & $24(56)$ \\
\hline & MLSE parametric & $149\left(2.7 \times 10^{3}\right)$ & $68\left(1.2 \times 10^{3}\right)$ & $31\left(1.4 \times 10^{3}\right)$ \\
\hline & MLSE Histograms & $149\left(2.7 \times 10^{3}\right)$ & $O(0)$ & $1.7 \times 10^{4}\left(3.1 \times 10^{5}\right)$ \\
\hline \multirow{3}{*}{$\begin{array}{c}111 \mathrm{~Gb} / \mathrm{s} \\
\text { POMLUX } \\
\text { DQSK }\end{array}$} & FFE & $20(44)$ & $20(44)$ & $40(88)$ \\
\hline & MLSE parametric & $1.7 \times 10^{4}\left(2.6 \times 10^{8}\right)$ & $7.8 \times 10^{3}\left(1.1 \times 10^{8}\right)$ & $1.3 \times 10^{3}\left(5.1 \times 10^{7}\right)$ \\
\hline & MLSE Histograms & $1.7 \times 10^{4}\left(2.6 \times 10^{8}\right)$ & \begin{tabular}{|l|}
$0(0)$ \\
\end{tabular} & $2 \times 10^{6}\left(3 \times 10^{10}\right)$ \\
\hline
\end{tabular}

Table 1: Required operations for different equalizers.

In table 1, the computational power requirement is divided into three categories, namely the number of required complex summations/subtractions, complex multiplications, and memory locations (for storing channels histograms and look up tables). It is clear that for relatively low data rates (e.g. $10 \mathrm{~Gb} / \mathrm{s}$ ) the required summations and multiplications for MLSE are comparable to FFE. The lower optical complexity of direct-detection with MLSE is then a significant advantage compared to a more complex coherent receiver. On the other hand, for data rates of $43 \mathrm{~Gb} / \mathrm{s}$ and $111 \mathrm{~Gb} / \mathrm{s}$, one can notice that the number of required summations, multiplications and memory locations increases exponentially with the increase of CD. This makes MLSE an unattractive solution for a CD tolerance of $\pm 1000 \mathrm{ps} / \mathrm{nm}$ and more. Another important point that can be concluded from table 1 is that using multilevel modulation formats, such as DQPSK and POLMUX-DQPSK, one can effectively reduce the number of required MLSE states required at a certain $C D$ level. This significantly reduces the number of required operations.

Tabel 1 shows that for higher data rates (e.g. $40 \mathrm{~Gb} / \mathrm{s}$ and higher), the linear FFE represents the optimal choice in terms of computational power requirements. Therefore, an FFE in a butterfly structure together with coherent detection is used for $111-\mathrm{Gb} / \mathrm{s}$ POLMUX-DQPSK signal [7]. In Fig. 1, we investigate the effect of using a few number of DFE taps to assist the FFE taps in equalizing $C D$, by means of simulation. From the figure it is evident that as long as the number of FFE taps is sufficient for compensating $C D$, there is almost no OSNR penalty compared to back-to-back, regardless the number DFE taps used. Once the number of FFE taps is limited, the OSNR penalty increases rapidly and only by then, the DFE taps start to provide a very limited assistance. However, implementing a feedback path for DFE is challenging for such high data rates and hence we conclude that FFE only equalization is more optimal than FFE+DFE.

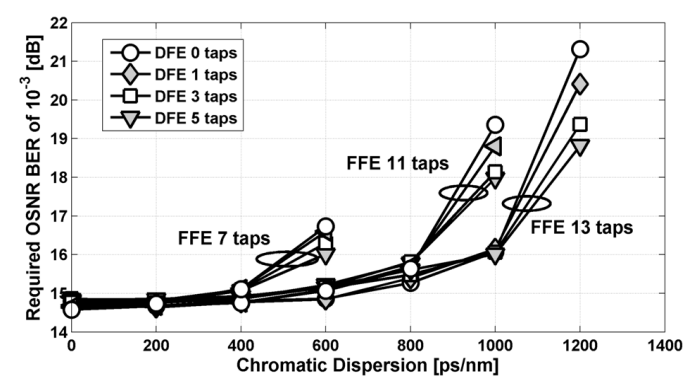

Fig. 1: Required OSNR vs. CD for 112 Gb/s POLMUX-RZ$D Q P S K$ signal with different number of FFE/DFE taps

\section{Conclusions}

In this paper we discussed different equalization techniques for $D(Q) P S K$ modulation. In case of direct detection, we demonstrate that one should use either a conventional MLSE with a shortened MZDI or a joint-MLSE. However, for data rates of $40 \mathrm{~Gb} / \mathrm{s}$ and above the high number of required operations makes MLSE an unrealistic solution. As such, FFE is the optimum choice for the equalization of linear transmission impairments at higher data rates, given that coherent detection is employed.

\section{References}

1. T. Freckmann et al., OFC2008, paper OTuO6.

2. C. Xia, et al., JLT, Vol. 25, No. 4, April 2007.

3. A. Faebert et al., ECOC 2004, paper Th4.1.5.

4. I. Lobato et al., ECOC 2006, paper We2.5.3.

5. M. S. Alfiad et al., "Maximum Likelihood Sequence Estimation for Optical Phase-Shift Keyed Modulation Formats", to be published in JLT.

6. M. Cavallari, et al., OFC2004, paper TuG2.

7. C. R. Fludger, et al., JLT 2008, 26(1), p.p. 64-72. 